\title{
Comparison of two dimensional immunoelectrophoresis and multimer analysis in the study of von Willebrand factor
}

\author{
MARgaRet A HOWARD, A OATES, B G FIRKIN From the Department of Medicine, Monash Medical \\ School, Prahran, Melbourne, Australia
}

SUMmARY To assess the validity of the multimeric analysis of von Willebrand factor (vWf), this technique was compared with two dimensional immunoelectrophoresis using samples of purified $\mathrm{vWf}$ obtained by gel filtration and plasma samples from a patient with severe von Willebrands disease who was receiving prophylaxis with cryoprecipitate. It is concluded that except for specialised clinical and research purposes, two dimensional immunoelectrophoresis provides a clear picture of the multimeric composition of the vWf molecule, and that this is sufficient for routine research and clinical use, without having to confirm the data by multimeric analysis.

A functional von Willebrand factor (vWf) molecule is required for adhesion of platelets to endothelial cell surfaces at the site of injury. VWf circulates as a complex with procoagulant factor VIII (FVIII:C), which acts as a cofactor for the factor IXa mediated conversion of factor $\mathrm{X}$ to the activated form factor Xa. The vWf molecule confers stability on FVIII:C activity, and perhaps this stabilising function explains the association of these two unrelated molecules in the circulation. The subunit size of the $\mathrm{vWf}$ molecule has been reported to be between $225 \mathrm{~K}$ and $278 \mathrm{~K}^{1-5}$ Subunits aggregate via disulphide bonds to form a series of circulating multimers with molecular weights ranging from 800 to $2000 \mathrm{kD}$. $^{1-5}$

In vitro the functional activity of $v W f$ can be measured by several different assays. The most commonly used are adhesion of platelets to a column of glass beads, ${ }^{6}$ ristocetin induced aggregation of formaldehyde fixed washed platelets (RCoF), ${ }^{7}$ botrocetin induced aggregation of paraformaldehyde fixed washed platelets $(\mathrm{BCoF}),{ }^{8}$ and more recently monoclonal antibodies have been produced which are directed to functional sites on the vWf molecule. ${ }^{9-11}$ Several assays are available for the measurement of the antigenic activity of $\mathrm{vWf}(\mathrm{vWf}: \mathrm{Ag})$. These include quantitative immunoelectrophoresis (EIA) using heterologous antibodies, ${ }^{12}$ enzyme linked immunosorbent assay (ELISA), ${ }^{13}$ two dimensional immunoelectrophoresis (CIE), ${ }^{14}$ and analysis of the polymer distribution on sodium dodecyl sulphate (SDS)

Accepted for publication 5 August 1987 agarose electrophoresis. ${ }^{15} \mathrm{~A}$ combination of these techniques is used to make the diagnosis of haemophilia A or von Willebrand's disease (vWd).

Both agarose CIE and SDS-agarose multimer analysis provide a means of visualising the polymer distribution of the vWf molecule by examining an autoradiograph or stained gel following electrophoresis of the test sample. Recently many reviewers seem to be demanding multimeric analysis of $\mathrm{vWf}$ before accepting data on vWf as being adequate. We question whether this is always appropriate and show that one technique compliments the other and that in most instances the more readily available CIE would suffice except for diagnosis of the new variants of $\mathrm{vWd}$ and for specific research purposes. The relative merits of these two techniques are addressed in this paper by examining fractions of purified material obtained from a gel filtration column and plasma samples obtained from a patient during a therapeutic infusion cryoprecipitate.

\section{Material and methods}

Blood collection and the preparation of platelet poor plasma was carried out at room temperature as previously described. ${ }^{16}$ Serum was prepared by allowing whole blood to clot at $37^{\circ} \mathrm{C}$ for two hours, then overnight at $4^{\circ} \mathrm{C}$. Normal pooled plasma consisted of aliquots of platelet poor plasma obtained from 100 healthy volunteers, which were pooled, snap frozen, and stored at $-70^{\circ} \mathrm{C}$ until required, then thawed at $37^{\circ} \mathrm{C}$. RCoF and BCoF assays were performed as previously described. ${ }^{717}$ Rabbit antibodies against 
human vWf were raised, purified, and radiolabelled with ${ }^{125}$ Iodine and used for EIA and radio-CIE as previously outlined. ${ }^{16}$ In the experiments where $5 \%$ polyethylene glycol 6000 (PEG) (Ajax Chemicals, Australia) was used in the radio-CIE, 5\% (PEG) w/v was dissolved in the electrophoresis buffer, $0.9 \%$ agarose (SeaKem ME, FMC) added, the solution boiled, then maintained at $56^{\circ} \mathrm{C}$ until antibody was added. Gel Bond (FMC) was used as backing for the agarose gels. The running conditions for PEG-radioCIE were the same as those for radio-CIE in the absence of PEG.

Purification of $\mathrm{vWf}$ and preparation of fractions of differing molecular weight were carried out as follows. Whole blood was collected into a $1 / 10$ volume of $3.8 \%$ trisodium citrate, containing $100 \mathrm{U} / \mathrm{ml}$ heparin (Weddel Pharmaceuticals) and $100 \mathrm{U} / \mathrm{ml}$ aprotinin (Bayer Pharmaceuticals, Australia). Platelet poor plasma was obtained by centrifuging at $2000 \mathrm{~g}$ for 20 minutes. Soybean trypsin inhibitor (SBTI) (Sigma) $0.1 \mathrm{mg} / \mathrm{ml}$ and phenyl methyl sulphonyl fluoride (PMSF) (Sigma) $1 \mathrm{mM}$ were then added. The platelet poor plasma was centrifuged at $12000 \mathrm{~g}$ for 20 minutes at $4^{\circ} \mathrm{C}$. Bentonite $(10 \mathrm{mg} / \mathrm{ml})$ (Sigma) was added to the supernatant and the mixture stirred for 30 minutes at room temperature, then centrifuged at $24000 \mathrm{~g}$ for 20 minutes. The supernatant was taken to $30 \%$ saturation $(w / v)$ with ammonium sulphate and cooled at $4^{\circ} \mathrm{C}$ for one hour, then centrifuged at $24000 \mathrm{~g}$ for 20 minutes at $4^{\circ} \mathrm{C}$. The precipitate was dissolved at $37^{\circ} \mathrm{C}$ in $0.05 \mathrm{M}$ tris, $0 \cdot 15 \mathrm{M}$ sodium chloride buffer $(\mathrm{pH} 7 \cdot 4)$ containing $10 \mathrm{U} / \mathrm{ml}$ heparin, $10 \mathrm{U} / \mathrm{ml}$ aprotinin, $0.1 \mathrm{mg} / \mathrm{ml} \mathrm{SBTI}$, and $1 \mathrm{mM}$ PMSF (eluting buffer), and an equal volume of $25 \%$ sucrose (Ajax, Australia) was added. This solution was centrifuged at $100000 \mathrm{~g}$ for 30 minutes at $20^{\circ} \mathrm{C}$. The infranatant $(3 \mathrm{ml})$ was applied to a bio-Gel A 15M (100-200 mesh) (Bio-Rad) column $(2.5 \times 100 \mathrm{~cm})$ and eluted with eluting buffer. Fractions $(1 \mathrm{ml})$ were collected and stored at $4^{\circ}$ until analysed.

Multimer analysis was carried out as described ${ }^{15}$ with the following modifications. The base of the vertical plate assembly was sealed with $0.9 \%$ agarose (SeaKem ME, Marine Colloids), dissolved by boiling in $0.005 \mathrm{M}$ sodium barbitone (Sigma), $0.0075 \mathrm{M}$ barbitone (Sigma), and 0.0625M sodium chloride $\mathrm{pH} 7.4$ (gel buffer). One per cent agarose, $0 \cdot 2 \%$ SDS, and 6M urea were boiled in the gel buffer then equilibrated at $56^{\circ} \mathrm{C}$ before pouring between the plates. The $1.5 \mathrm{~mm}$ thick gel was solidified at $4^{\circ} \mathrm{C}$ and used within 24 hours of pouring. The gel was transferred to gelbond (Marine Colloids), sample wells were cut $(2 \times 10 \mathrm{~mm})$, and the gel placed in the electrophoresis tank. Samples were diluted in gel buffer containing $8 \mathrm{M}$ urea and $0.5 \%$ SDS, then incubated at $56^{\circ} \mathrm{C}$ for 60 minutes. A 50 ul sample was applied to the gel and electrophoresis carried out in $0.075 \mathrm{M}$ sodium barbitone (BDH), 0.015M barbitone (BDH), pH 8.6 at 13 $\mathrm{mA} /$ gel for four hours, or until the marker dye had moved $8 \mathrm{~cm}$. The gels were fixed in $25 \%$ isopropanol, $10 \%$ acetic acid for 16 hours at room temperature, then washed extensively with distilled water, incubated in $0.15 \mathrm{M}$ phosphate buffered saline, $0.02 \%$ sodium azide, and $0.1 \%$ bovine serum albumin for 16 hours at room temperature. This buffer was replaced with $100 \mathrm{ng}$ of ${ }^{125} \mathrm{I}$-rabbit antihuman vWf $(1000-1500$ $\mathrm{cpm} / \mathrm{ng}$ ) in $0.15 \mathrm{M}$ phosphate buffered saline, $0.02 \%$ sodium azide, $0 \cdot 1 \%$ bovine serum albumin and incubated for 16 hours at room temperature, then washed with three changes of $0.015 \mathrm{M}$ phosphate buffered saline, $0 \cdot 1 \%$ bovine serum albumin, and $0.02 \%$ sodium azide for 30 minutes each. The gel was then dried and autoradiographed.

Several samples of plasma were obtained from a patient with severe von Willebrand's disease during an infusion with cryoprecipitate. The plasma concentrations of FVIII:C/vWf:Ag/RCoF/BCoF before infusion were below the limits of detection for each assay.

Informed consent was obtained from this patient, in keeping with the policy of Monash University human ethics committee.

\section{Results}

The semipurified vWf, which was used for further purification of $\mathrm{vWf}$ by gel filtration on a Bio-Gel column, was similar to the starting plasma in terms of its function and structure. The vWf:Ag/RCoF/BCoF of the semipure $\mathrm{vWf}$ of a representative fractionation was 9.6/8.0/5.4 U/ml compared with $0.92 / 1 \cdot 0 / 0.6 \mathrm{U} /$ $\mathrm{ml}$ of the starting platelet poor plasma. Radio-CIE and the vWf multimer distribution of this material are shown in fig 1, alongside the starting material. No obvious changes occurred during purification of $\mathrm{vWf}$ by this technique.

Fig 2 shows the elution profile obtained for a typical purification and fractionation of $\mathrm{vWf}$ from a Bio-Gel column (six similar experiments were performed). The void volume fractions with small amounts of protein (indicated by the low optimum density) contains the highest vWf:Ag, RcoF, and BCoF activities. More BCoF activity was present in later eluting fractions than RCoF activity. Fraction numbers 40-90 were subjected to radio-CIE and multimer analysis (figs 3 and 4).

Radio-CIE of selected column fractions between numbers 40-90 showed a sequential change from slowly migrating (high molecular weight polymers (fig $3 \mathrm{a}-\mathrm{c}$ ) to intermediate sized polymers (fig $3 \mathrm{~d}-\mathrm{e}$ ) and faster migrating (low molecular weight) polymers (fig $3 \mathrm{f}-\mathrm{h}$ ). Each of these fractions was subjected to 


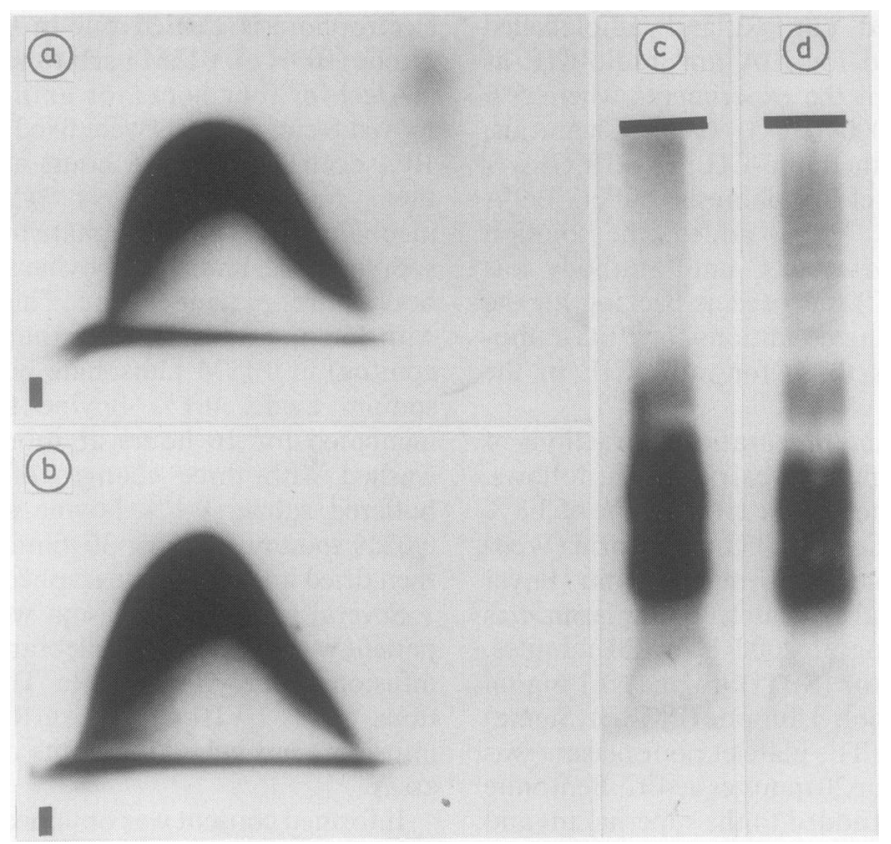

Fig 1 (a) Radiocrossed immunoelectrophoresis (CIE) of 50 $\mu$ l donor plasma against ${ }^{125}$ I-anti human $v W f: A g$. (b) CIE of $50 \mu$ of 1/10 dilution of semipurified $v W f: A g$. Solid bar indicates starting well. (c) Sodium dodecyl sulphate-agarose multimeric analysis of 1/80 dilution of donor plasma. (d) Sodium dodecyl sulphate-agarose multimeric analysis of 1/800 dilution of semipurified $v W f: A g$. Solid bar indicates point of application and thus position of high molecular weight multimers.

multimer analysis; the resultant autoradiographs are shown in fig 4. Multimer analysis of these fractions also showed a sequential elution from the column of high molecular weight polymers (fig $4 \mathrm{~b}-\mathrm{c}$ ), to intermediate sized multimers (fig $4 \mathrm{~d}-\mathrm{e}$ ), and the low molecular weight (fig $4 \mathrm{f}-\mathrm{h}$ ).

A further comparison between radio-CIE and multimer analysis was made using samples of plasma obtained from a patient with severe von Willebrand's disease during a therapeutic infusion of cryoprecipitate. The plasma from this patient contained only low molecular weight multimers of vWf, which were visible on SDS-agarose gel multimer analysis but were not detected by radio-CIE (fig 5). The sample taken 10 minutes after infusion contained both high molecular weight and low molecular weight of $\mathrm{vWf}$ seen both on radio-CIE and multimer analysis. During the next 13 hours there was a gradual return to the pattern of $\mathrm{vWf}$ polymer distribution seen on both radio-CIE and multimer analysis before infusion (fig 5).

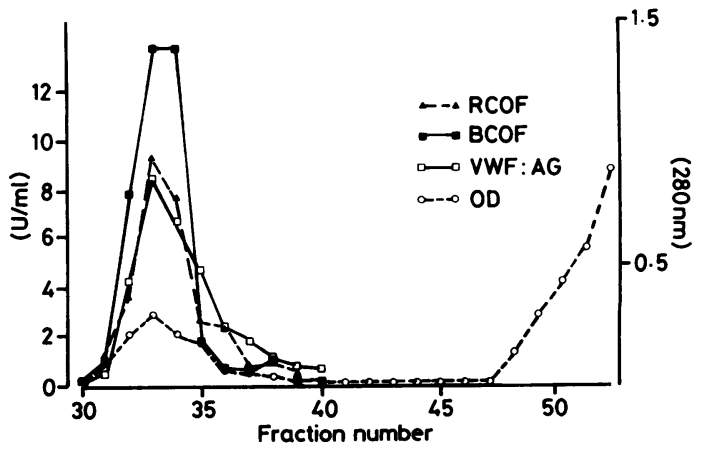

Fig 2 Elution profile of $3 \mathrm{ml}$ of semipurified $v W f: A g$ (vWf: Ag 16.5, RCof 15.2, U/ml) from Bio Gel A 15M (mesh 100-200) column $(2.5 \times 95 \mathrm{~cm})$, at a flow rate of $12 \mathrm{ml}$ hour, $1 \mathrm{ml}$ fractions were collected. $\bigcirc---\bigcirc$ optimum density, $\square \longrightarrow \square v W f: A g, \Delta--\Delta$ ristocetin induced aggregation of formaldehyde fixed washed platelets, $\square$ botrocetin induced aggregation of paraformaldehyde fixed washed platelets. 


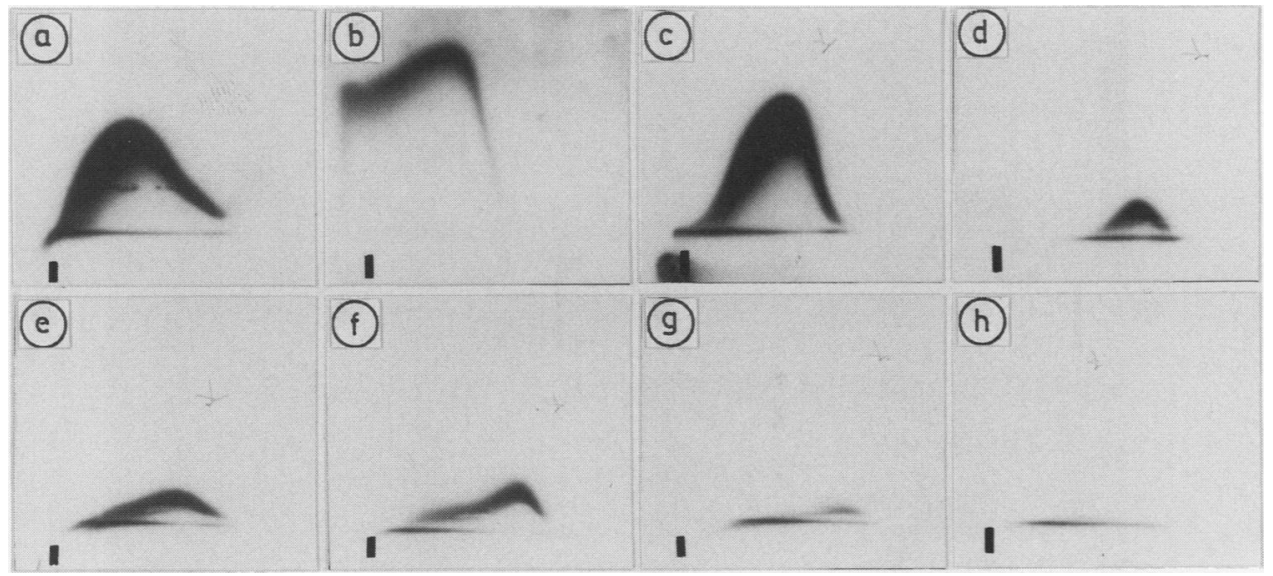

Fig 3 CIE of selected fractions from Bio Gel A 15 M elution presented in fig 2. (a) Normal pooled plasma; (b) fraction 40; (c) fraction 50; (d) fraction 55; (e) fraction 65; ( $)$ fraction 75; (g) fraction 85;

(h) fraction 90. Solid bar indicates starting well: $50 \mu l$ of undiluted samples were applied to each well.

A proteolytic product of $\mathrm{vWf}$ termed von Willebrand factor: fast migrating protein (vWf:FMP) was also detectable by radio-CIE (fig 6). The vWf:FMP formed a precipitant are against the rabbit antivWf used in the radio-CIE and was readily seen in a more anodal position than vWf:Ag in normal serum, but not in a normal plasma sample (fig 6a). Inclusion of $5 \%$ polyethylene glycol in the agarose used for the radio-CIE facilitated the detection of VWf:FMP in normal plasma (fig 6B).

\section{Discussion}

Analysis of the multimeric composition of vWf:Ag is carried out by either SDS-agarose gel electrophoresis with subsequent exposure to anti-vWf serum or by two dimensional immunoelectrophoresis, where anti-vWf serum is incorporated into the second dimension gel. Comparisons were made between these two techniques using samples of vWf:Ag obtained under differing circumstances. A good correlation was noted

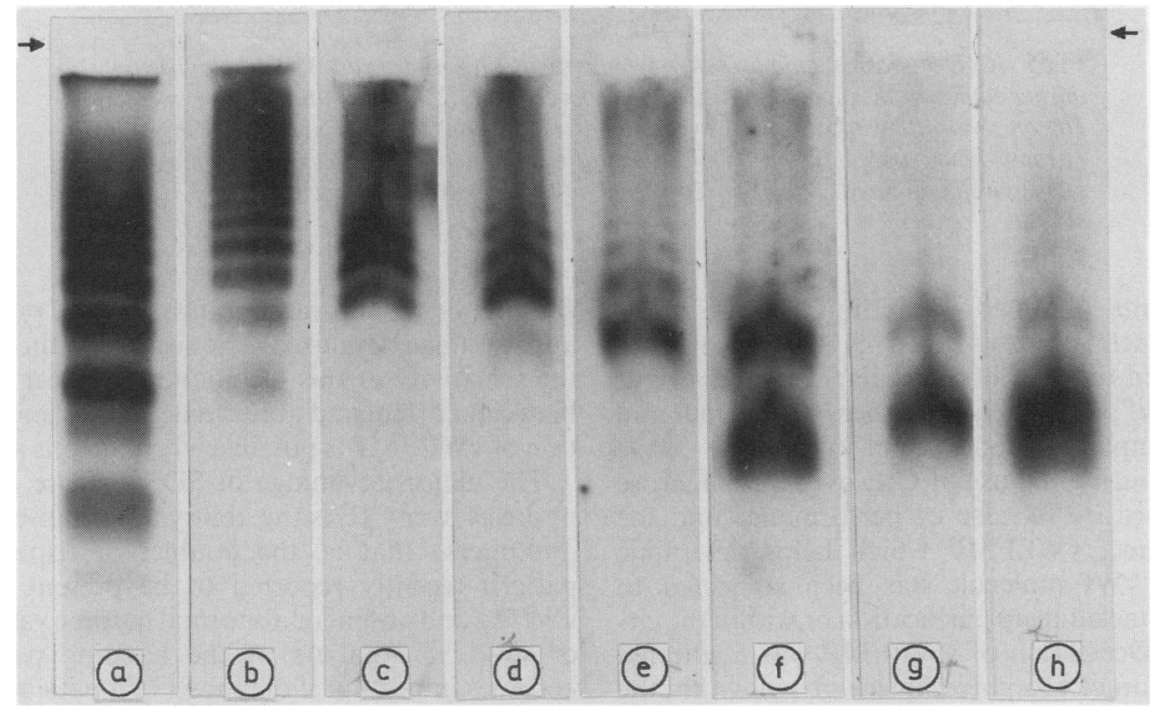

Fig 4 sodium dodecyl sulphate-agarose multimeric analysis of selected fractions from Bio Gel A 15M elution presented in fig 2. (a) Normal pooled plasma; (b) fraction 40; (c) fraction 50; (d) fraction 55; (e) fraction 65; $(f)$ fraction 75; $(\mathrm{g})$ fraction $85 ;(\mathrm{h})$ fraction 90 . Arrow indicates point of application. Samples were diluted 1/40 in reducing buffer then a further $1 / 5$ using sodium dodecyl sulphate-agarose gel before application to starting well. 


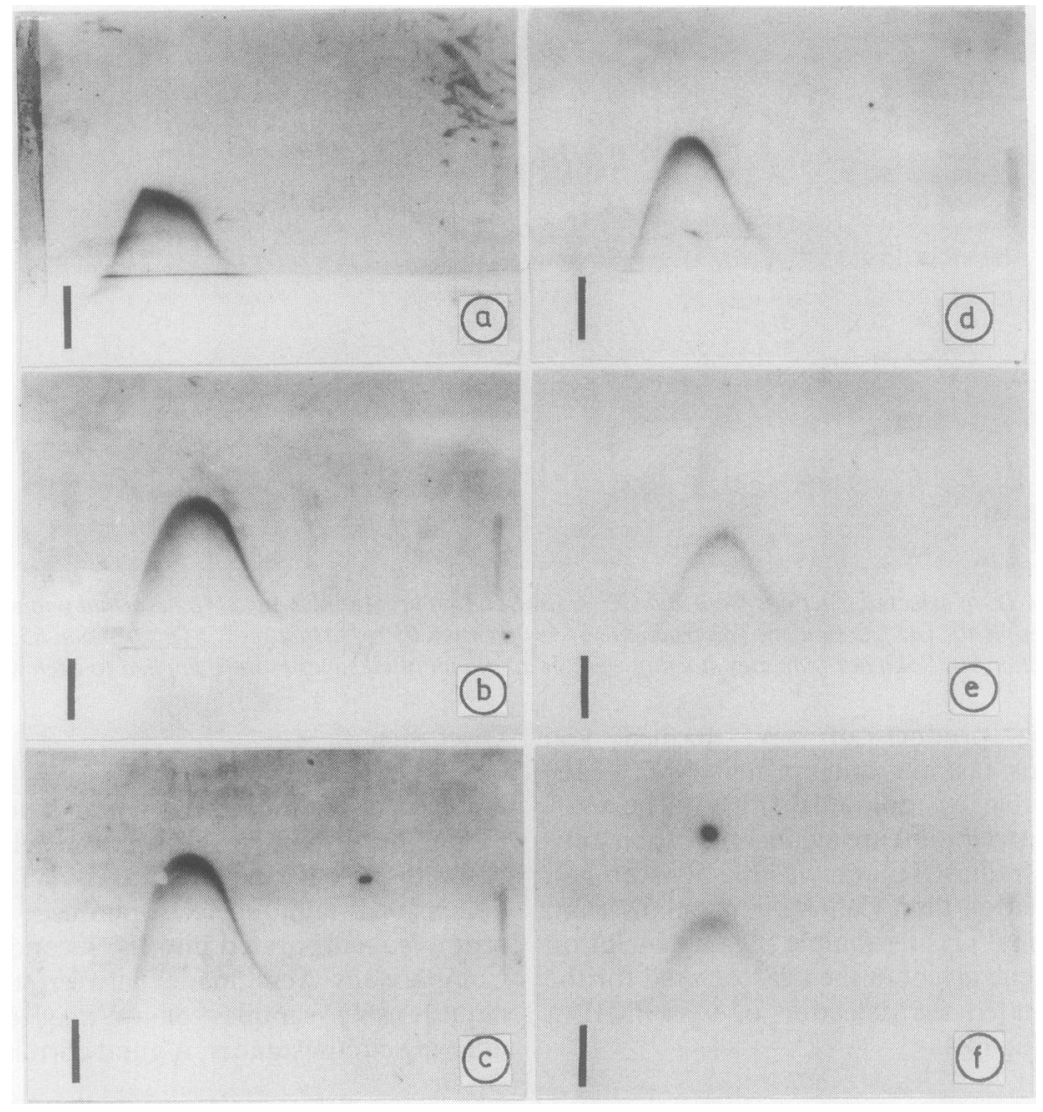

Fig 5 CIE of plasma samples taken from patient with severe von Willebrand disease during course of therapeutic infusion of cryoprecipitate. (a) Ten minutes after infusion; (b) one hour after infusion; (c) two hours after infusion; (d) four hours after infusion; (e) nine hours after infusion; $(f) 13$ hours after infusion. All samples were applied to staring well undiluted. Solid bar represents point of application of samples.

between results obtained by radio-CIE and SDSagarose gel electrophoresis (figs 1-5). Both techniques clearly showed the overall molecular weight distribution of the vWf polymers using either purified material or plasma samples as the source of vWf:Ag.

Points favouring the use of CIE over SDS-agarose electrophoresis are its ease of performance and the ability to detect vWf:FMP which helps determine whether the vWf molecule has been subjected to proteolytic attack during purification or within the circulation. ${ }^{18-20}$ Dectection of vWf:FMP was facilitated by the inclusion of $5 \%$ polyethylene glycol within the antibody containing gel, which improved the precipitability of formed antigen-antibody complexes (fig 6).

Visualisation of the antigen-antibody complexes using CIE can be achieved by either Coomassie blue staining or by autoradiography when a radiolabelled anti-vWf has been used. The second method increases the sensitivity of this technique, but clear distinction between normal and abnormal samples and the detection of vWf:FMP is possible when the gels are stained.

The major advantage of SDS-agarose gel electrophoresis over CIE is the ability to visualise individual multimers - that is, the doublet or triplet banding pattern recently reported to be present in normal vWf:Ag and absent or abnormal in some variant forms of $\mathrm{vWd}^{2122}$ Analysis of the banding pattern only becomes important if diagnosis of a patient with $\mathrm{vWd}$ beyond the general classification of type I-III is required. Subclassification of patients with type IIB $v W d$ can be made on the basis of the presence of the greater sensitivity of platelet rich plasma towards low concentrations of ristocetin. ${ }^{2324}$ Distinction of type IIB 


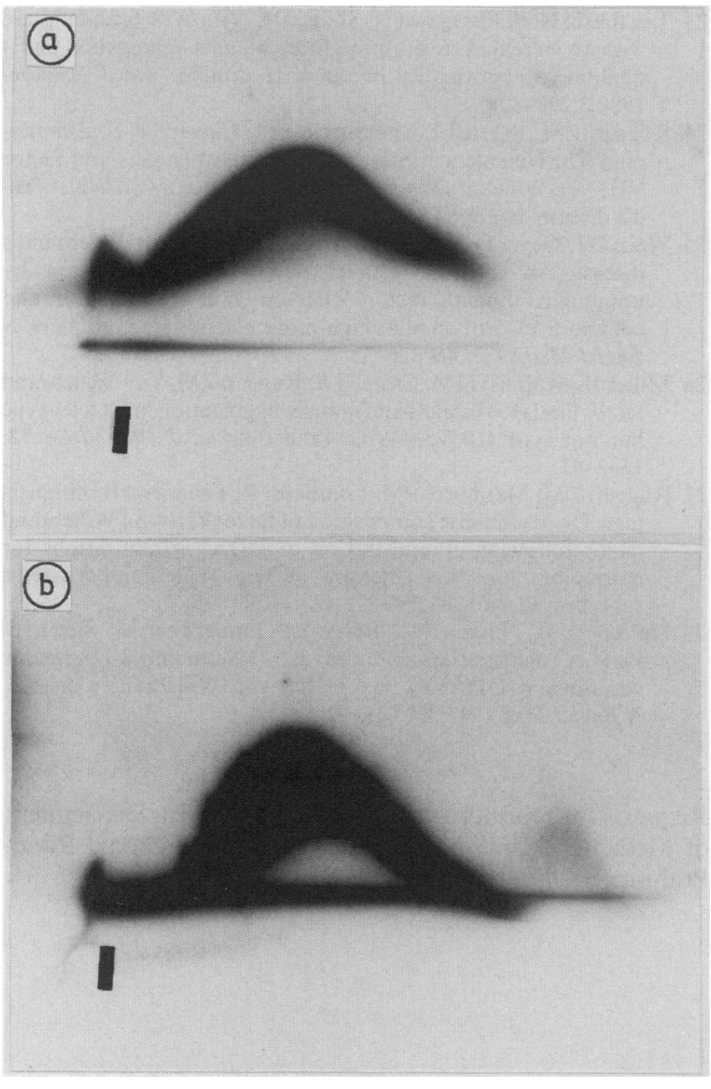

Fig 6 CIE of normal pooled plasma $(a)$ in the absence of $P E G ;(b)$ in the presence of $5 \%$ PEG. $50 \mu$ l of undiluted samples were applied to starting wells.

patients from those with platelet type vWd is possible by the use of cryoprecipitate as a reagent: this will aggregate platelets from patients with platelet type vWd but not those from patients with type IIB $\mathrm{vWd}{ }^{25}{ }^{26}$ From a therapeutic point of view these are currently the only group of patients for which accurate diagnosis is essential due to the possibility of the development of thrombocytopenia following infusion of 1-deamino-8-D-arginine vasopressin (DDAVP). ${ }^{27} 28$ Thrombocytopenia results from release of the high molecular weight multimers from storage sites. The presence of these high molecular weight multimers is presumably abnormal in type IIB vWd, but when released, cause aggregation of the circulating platelets; in platelet type vWd it is the release of normal high molecular weight vWf multimers which causes aggregation of the abnormal platelets and hence their subsequent removal from the circulation. Therefore in these two situations thrombocytopenia results from release of high molecular weight $\mathrm{vWf}$ multimers due to aggregation of circulating platelets.

Accurate diagnosis of $\mathrm{vWd}$ can be made using CIE combined with RCoF activity, vWf:Ag concentrations, and testing of the sensitivity of platelet rich plasma to low concentrations of ristocetin. CIE is a technique which lends itself to use with the vWf:Ag assay, using either Coomassie blue staining or radiolabelled anti-vWf combined with autoradiography. We conclude that SDS-agarose electrophoresis is only necessary for specialist or research laboratories where detailed analysis of the multimeric structure of the $\mathrm{vWf}$ molecule is required.

Ristocetin was a gift from Lundbeck and Co, Copenhagen, Denmark. We thank Dr Kathy Thomas for the photograph of the CIE shown in fig 5. M A Howard and A Oates were supported by a National Health and Medical Research Council of Australia grant.

\section{References}

1 Hoyer LW, Shainoff JR. Factor VIII-related protein circulates in normal human plasma as high molecular weight multimers. Blood 1980;55:1056-9.

2 Pietu G, Obert B, Larrieu M-J, Meyer D. Structure-function relationship of factor VIII/von Willebrand factor-Application to the study of variant von Willebrand disease and cryosupernatant prepared from normal plasma. Thromb Res 1980;19: 671-85.

3 Marchesi SL, Shulman NR, Gralnick HR. Studies on the purification and characterisation of human factor VIII. J Clin Invest 1972;51:215-61.

4 Titani K, Kumar S, Takio K, et al. Amino acid sequence of human von Willebrand factor. Biochem $J$ 1986;25:3171-84.

5 Chopek MW, Girma J-P, Fujikawa K, Davie EW, Titani K. Human von Willebrand factor: a multivalent protein composed of identical subunits. Biochem J 1986;25:3146-55.

6 Salzman EW. Measurement of platelet adhesiveness: a simple in vitro technique demonstrating an abnormality in von Willebrand's disease. J Lab Clin Med 1964;62:724-35.

7 MacFarlane DE, Stibbe J, Kirby EP, Zucker MB, Grant RA, McPerson JA. A method for assaying von Willebrand factor (Ristocetin cofactor). Thromb Diath Haem 1975;34:306-8.

8 Brinkhous KM, Read MS. Use of venom coagglutinin and lyophilized platelets in testing for platelet-aggregating von Willebrand factor. Blood 1980;55:17-20.

9 Bowie EJW, Fass DN, Katzman JA. Functional studies of von Willebrand factor using monoclonal antibodies. Blood 1983;62:146-51.

10 Meyer D, Baumgartner HR, Edgington TS. Hybridoma antibodies to human von Willebrand factor II. Relative role of intramolecular loci in mediation of platelet adhesion to the subendothelium. Br J Haematol 1984;57:609-20.

11 Chand S, McCraw A, Hutton R, Tuddenham EGD, Goodall AH. A two-site, monoclonal immunoassay for von Willebrand factor-demonstration that vWF function resides in a conformational epitope. Thromb Haemostas 1986;55:318-24.

12 Zimmerman TS, Hoyer LW, Dickson L, Edgington TS. Determination of the von Willebrand's disease antigen (factor VIIIrelated antigen) in plasma by quantitative immunoelectrophoresis. J Lab Clin Med 1975;86:152-9.

13 Short PE, Williams CE, Picken AM, Hill FGH. Factor VIII related antigen: an improved enzyme immunoassay. Med Lab Sci 1982;39:351-5. 
14 Koutts J, Walsh PN, Plow EF, Fenton J, Bouma BN, Zimmerman TS. Active release of human platelet factor-VIII related antigen by adenosine diphosphate, collagen and thrombin. J Clin Invest 1978;62:1255-63.

15 Ruggeri ZM, Zimmerman TS. The complex multimeric composition of factor VIII/von Willebrand factor. Blood 1981;57: 1140-3.

16 Howard MA, Hau L, Perkin J, Thomas KB, Firkin BG. Causes for the discrepancies in the measurements of factor VIII antigen. Thromb Res 1980;19:63-72.

17 Howard MA, Perkin J, Salem HH. Firkin BG. The agglutination of human platelets by botrocetin: evidence that botrocetin and ristocetin act at different sites on the factor VIII molecule and platelet membrane. Br J Haematol 1984;57:25-35.

18 Thomas KB, Howard MA, Salem HH, Firkin BG. Fast migrating protein, immunochemically related to human factor VIII, studied by crossed immunoelectrophoresis in agarose. $\mathrm{Br} J$ Haematol 1983;54:221-31.

19 Thompson EA, Howard MA. Proteolytic cleavage of human von Willebrand factor induced by enzyme(s) released from polymorphonuclear cells. Blood 1986;76:1281-5.

20 Montogomery RR, Johnson J. Specific FVIII-related antigen fragmentation: An in vivo and in vitro phenomenon. Blood 1982;60:930-9.

21 Ruggeri ZM, Nilsson IM, Lombardi R, Holmberg L, Zimmerman TS. Aberrant multimeric structure of vonWillebrand factor in a new variant of von Willebrand's disease (type IIC). J Clin Invest 1982;70:1124-7.

22 Kinoshita S, Harrison J, Lazerson J, Abildgaard. A new variant of dominant type II von Willebrand's disease with aberrant multimeric pattern of factor VIII-related antigen (type IID). Blood 1984;63:1369-71.
23 Takahashi H, Sakuragawa N, Shibata A. Von Willebrand disease with an increased ristocetin-induced platelet aggregation and a qualitative abnormality of the VIII protein. Am J Hematol 1980;8:299-308.

24 Ruggeri ZM, Pareti FI, Mannuccio PM, Ciavarella N, Zimmerman TS. Heightened interaction between platelets and factor VIII/von Willebrand factor in a new subtype of von Willebrand's disease. $N$ Engl J Med 1980;3021047-51.

25 Weiss HJ, Meyer D, Rabinowitz R, et al. Pseudo-von Willebrand's disease An intrinsic platelet defect with aggregation by unmodified human factor VIII/von Willebrand factor and enhanced adsorption of its high-molecular-weight multimers. $N$ Engl J Med 1982;306:326-33.

26 Miller JL, Kupinski JM, Castella A, Ruggeri ZM. Von Willebrand factor binds to platelets and induces aggregation in platelet-type but not type IIB von Willebrand disease. J Clin Invest $\mathbf{7 2}$ $1532-42$.

27 Ruggeri ZM, Mannucci PM, Lombardi R, Federici AB, Zimmerman TS. Multimeric composition of factorVIII/von Willebrand factor following administration of DDAVP:Implications for pathophysiology and therapy of von Willebrand's disease subtypes. Blood 1982;59:1272-8.

28 Holmberg L, Nilsson IM, Borge L, Gunnarsson M, Sjorin E. Platelet aggregation induced by 1-desamino-8-D-arginine vasopressin (DDAVP) in type IIB von Willebrand's disease. N Engl J Med 1983;309:816-21.

Requests for reprints to: Dr Margaret Howard, Department of Medicine, Monash Medical School, Commercial Road, Prahran, Melbourne, Australia. 